\title{
Access to Resources for Substance Users in Harlem, New York City: Service Provider and Client Perspectives
}

\author{
Sandro Galea, MD, MPH \\ Stephanie H. Factor, MD, MPH \\ Ann-Gel Palermo, MPH \\ Daniel Aaron, BA \\ Eric Canales \\ David Vlahov, $\mathrm{PhD}$
}

\begin{abstract}
The Urban Research Center (URC) in Harlem, New York City, is a collaboration of community members, service providers, and academics. A Community Advisory Board (CAB) meets regularly to formulate priorities for action and to direct research. A conceptual model of social determinants of health relevant to the Harlem community was developed. Early meetings of the $\mathrm{CAB}$ identified substance use as a health concern in the Harlem community. Access to social services was identified as a key social determinant that should guide research and intervention efforts of the URC. Surveys of service providers and of substance users were carried out to quantify availability of information and barriers to access. This article discusses the $\mathrm{CAB}$ process that led to the model of social determinants, development of surveys, and interpretation of results. The authors also discuss survey results and how the URC will use these results to develop interventions.
\end{abstract}

The communities of East and Central Harlem have long had worse economic conditions (e.g., unemployment, poverty rate) and higher morbidity and mortality rates (e.g.,

Sandro Galea, Center for Urban Epidemiologic Studies, New York Academy of Medicine, New York; Division of Epidemiology, Columbia University Mailman School of Public Health, New York. Stephanie H. Factor, Center for Urban Epidemiologic Studies, New York Academy of Medicine, New York; Division of Preventive and Analytic Methods, Epidemiology Program Office, Centers for Disease Control and Prevention, Atlanta, Georgia. Ann-Gel Palermo, Community Advisory Board, Center for Epidemiologic Studies, New York Academy of Medicine, New York; Institute for Medicare Practice, Mount Sinai School of Medicine, New York. Daniel Aaron, Center for Urban Epidemiologic Studies, New York Academy of Medicine, New York. Eric Canales, Center for Urban Epidemiologic Studies, New York Academy of Medicine, New York; Community Advisory Board, Center for Epidemiologic Studies, New York Academy of Medicine, New York. David Vlahov, Center for Urban Epidemiologic Studies, New York Academy of Medicine, New York; Division of Epidemiology, Columbia University Mailman School of Public Health, New York.

Address reprint requests to Sandro Galea, Center for Urban Epidemiologic Studies, New York Academy of Medicine, 1216 Fifth Avenue, New York, NY 10029-5293; phone: (212) 822-7378; fax: (212) 876-6220; email: sgalea@nyam.org.

The authors would like to thank all members of the Urban Research Center Community Advisory Board who have contributed to data collection and who have provided helpful feedback about the article. The authors extend particular thanks to Mary Northridge for her thoughtful contributions to earlier versions of this article. This work was partly funded by a Centers for Disease Control and Prevention Urban Research Centers CoOperative Agreement U48/CCU209663-07.

Health Education \& Behavior, Vol. 29 (3): 296-311 (June 2002)

(C) 2002 by SOPHE

296 
infant mortality, homicide, asthma incidence) than most neighborhoods in the United States. ${ }^{1-4}$ The Urban Research Center (URC) in Harlem is a Centers for Disease Control and Prevention (CDC)-funded effort to carry out community-based participatory research on the social factors affecting the health of local residents. The New York City URC is housed at the Center for Urban Epidemiologic Studies (CUES) and is directed by a community advisory board $(\mathrm{CAB})$. The $\mathrm{CAB}$ meets monthly to formulate priorities for action and to advise and direct research. This article discusses the $\mathrm{CAB}$ process that identified access to social services as a key determinant of substance users' health, how surveys were developed to quantify barriers to access from both provider and client perspectives, and the results of these surveys.

The $\mathrm{CAB}$ is made up of community members, service providers, public health workers, and academics. Although initially conceived as an "advisory" board, the CAB is intimately involved in designing URC research and working with CUES staff members in the execution of research, interpretation of results, and dissemination of findings. During its monthly meetings, the CAB sets its research and action agenda. Potential projects are discussed, and interested $\mathrm{CAB}$ members form subcommittees, together with CUES staff members, to further develop projects that the CAB agrees to tackle. The subcommittees report back to the $\mathrm{CAB}$, and key issues and decisions are made by the $\mathrm{CAB}$ as a whole. $\mathrm{An}$ effort to reach consensus on most key decisions means that project development is an iterative process, with suggestions from the subcommittees being shaped by all members of the $\mathrm{CAB}$. In this particular project, the $\mathrm{CAB}$ first developed a conceptual framework relevant to the local community. In concert with the CUES staff, the CAB reviewed existing needs assessments in Harlem, prioritized pressing needs, and chose access to services for substance users as a research focus that could lead to small-scale immediate intervention. Members of the $\mathrm{CAB}$, particularly $\mathrm{CAB}$ members with personal experience or professional expertise in the areas being investigated, worked with the CUES staff to develop appropriate survey instruments. The entire $\mathrm{CAB}$ was involved in devising a sampling frame for the surveys and in recruiting service provider respondents. CUES staff members analyzed the results together with $\mathrm{CAB}$ members who are coauthors on this article. The results were presented to the whole $\mathrm{CAB}$; this guided interpretation of the results and the discussion are summarized in this article. The implications for practice in particular stem directly from $\mathrm{CAB}$ discussions and decisions about next steps and actions to take in response to the survey results. In this article, we describe each of these stages and conclude with implications of this research for action in Harlem.

\section{A GENERAL MODEL OF SOCIAL DETERMINANTS}

Early in the URC's development, CAB members and researchers sought to ground their work in a conceptual framework that drew on the existing literature and on the group's collective experience. As a first step, the CAB used information from the literature, group discussions, and from focus groups to develop a conceptual model that could direct research and interventions. At early meetings of the CAB, factors that were believed to cause or contribute to health were discussed, and potential research and intervention strategies were developed. Ideas were refined at each meeting and presented back to the group by specific session leaders at subsequent meetings. Through this process, a general model of social determinants was developed (Figure 1).

The model of social determinants includes social factors operating at different levels; as conceived in this model, social factors may be salutary (e.g., social support) or elicit 


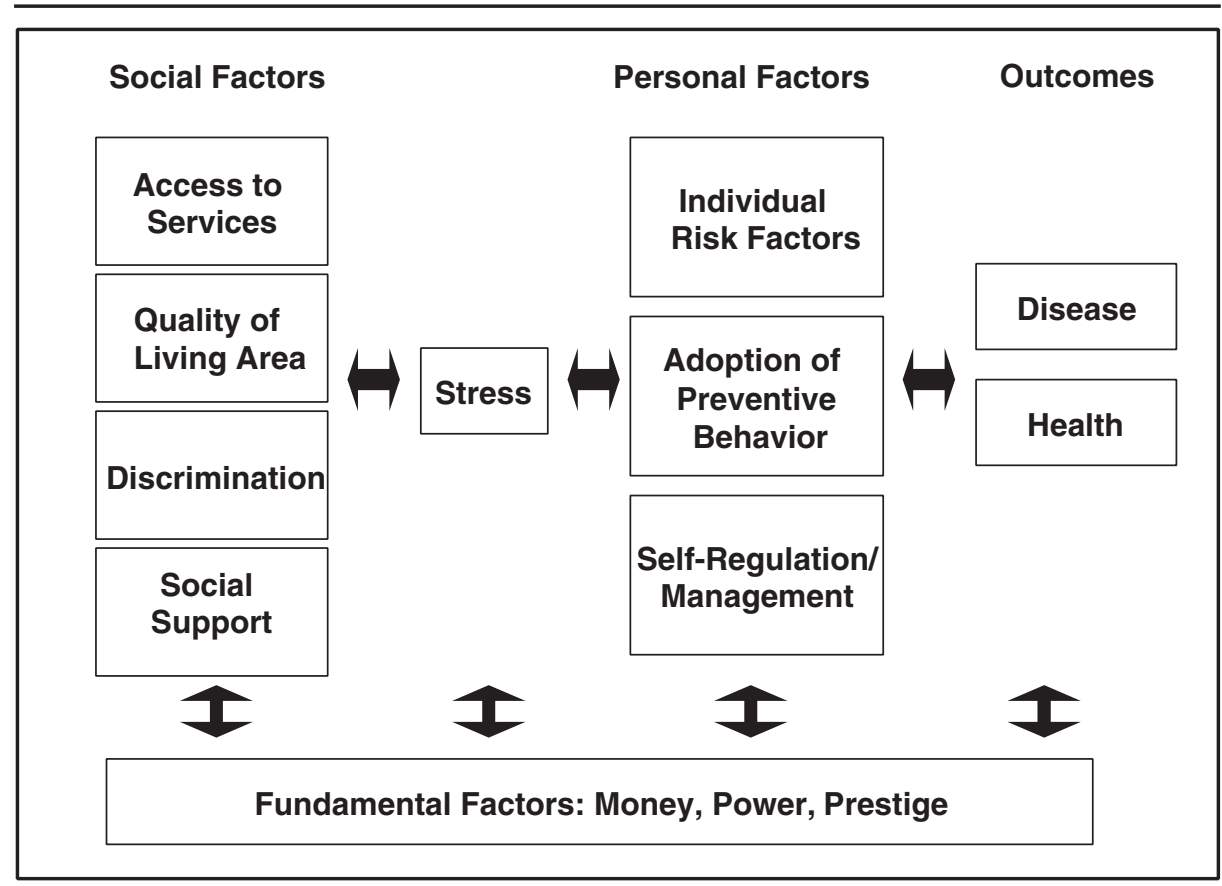

Figure 1. General model of social determinants developed by the New York Urban Research Center Community Advisory Board.

stress and coping responses. ${ }^{5,6}$ As an example of the latter, it was hypothesized that limited access to services results in demands exceeding individual adaptive resources, eliciting stress and subsequent poor health. ${ }^{7}$ Recognizing that different individuals recognize experiences as stressful depending on current life experiences, it was noted that many elements of this model are particularly applicable to vulnerable, marginalized populations ${ }^{6-8}$ Social support (including emotional, financial, and informational support), a protective social factor, and discrimination, a negative factor, were considered particularly important in the Harlem context and are highlighted in the model. Personal factors (e.g., individual preventive behavior, self-regulation) then mediate the effect of these social factors on individual health. ${ }^{6,7}$ Fundamental factors (e.g., money, power, prestige) affect all other levels of this model including communities, neighborhoods, and individuals. ${ }^{9}$ This model of social determinants guides research in the New York City URC. Although this model, as presented in Figure 1, is, by necessity, a simplified schematic, CAB discussions recognized the complexity inherent in the processes being summarized and left open the possibility of further expansion and clarification of the model.

\section{THE URBAN RESEARCH CENTER: UNDERSTANDING NEED IN HARLEM}

The long-term intent of the URC is to improve the health of the community by developing interventions to improve social factors affecting the health of Harlem residents. At the time of this research, the URC had been operating for less than 1 year. At this stage in the URC's development, $\mathrm{CAB}$ members felt it was important to develop and execute 
research that built on existing knowledge about the community and could lead to tangible action in the short term. CAB members and CUES staff workers thus carried out a comprehensive review of the needs assessments that had been done in the community from 1989 through $1999 .{ }^{10}$ There were 17 needs assessments considered; they included assessments conducted by Mount Sinai Hospital in Harlem, several assessments carried out by the city of New York, individual social service agencies, and one informal survey of grade school children..$^{10}$ Through iterative discussions during several CAB meetings, consensus developed in the $\mathrm{CAB}$ that there were three primary areas of need in Harlem that could benefit from URC research and intervention: (1) poor access to comprehensive and culturally sensitive health care, (2) poor housing, and (3) deterioration of environmental conditions. It is worth noting that this process was coincident with the development of the general model of social determinants described above. It was recognized that the primary areas of need identified corresponded principally to two domains in the model of social determinants being developed, namely, access to services and quality of living area (which encompasses both poor housing and deterioration of environmental conditions).

Subsequent CAB discussions also identified the overlap between these social factors and substance use, asthma, and infectious diseases (particularly HIV/AIDS) as primary areas of community concern. Although other agencies and studies had also identified substance use as a problem within the community, groups such as the East Harlem Community Health Committee's subgroup on substance use had not been active for several years. Substance use, an area in which CUES researchers had expertise, thus emerged as a principal early interest that addressed a pressing community concern and coincided both with a paucity of other intervention activity and with available URC resources. Individual socioeconomic conditions, social networks, access to community services, drug availability, and the criminalization of drug use were all identified as important factors that contribute to substance use and poor health of substance users in Harlem. In particular, it recognized that substance users may face significant stigmatization within the community and, as such, may face particular difficulties accessing appropriate services. CAB members decided that understanding barriers faced by substance users in accessing community services would be a first priority for research; this was primarily intended to guide subsequent interventions that would improve provision of community services for substance users. Identifying key features of service provision that were lacking and devising interventions to fill the gaps then became a key effort for the CAB.

In choosing to work on access issues (as opposed to housing or deteriorating environmental conditions), the $\mathrm{CAB}$ chose to focus on a pressing issue that offered the URC an opportunity to effect local change in a relatively short period of time. However, it was the CAB's intent to continue considering the other community concerns identified. Other ongoing URC projects aim to tackle the larger scale issues also identified as priorities by the $\mathrm{CAB}$.

\section{INFORMATION AND ACCESS TO RESOURCES FOR SUBSTANCE USERS}

Although service provision (both in terms of medical care and social services) is generally thought to account for a small proportion of the gains in human life expectancy during the past century, differentials in access and provision of care are frequently considered to be among the primary reasons for socioeconomic and racial disparities in health in the United States. ${ }^{11,12}$ Differences in access to services are widespread and involve both ser- 
vice availability and quality of care received. ${ }^{13}$ Some research has documented that medical care, in particular, has a greater impact on health for persons with lower socioeconomic status than for the general population. ${ }^{14} \mathrm{~A}$ lower number of social services, clinics, and hospitals in socioeconomically disadvantaged communities are a direct barrier to access, which manifests in later diagnosis of disease, delays in treatment, and comorbidity. Limited access to services is considered one of the key social factors that affect health in the model of social determinants formulated by the URC CAB.

Further complexity is introduced by a recognition that there is also a differential in quality-of-service provision. Disparities in health exist even where differences in economic status and insurance coverage are minimized. ${ }^{15}$ Persons of different socioeconomic class and different races receive different preventive and therapeutic services, ${ }^{16,17}$ receive care by different quality of providers, ${ }^{18}$ and receive different attention to similar presenting complaints. ${ }^{19}$ These differences in care given to persons of different socioeconomic class are compounded by decreased access to, and inferior quality of, health and social services and thus further contribute to poorer health of disadvantaged persons and communities.

Rates of disease (e.g., infectious diseases, mental health disorders) in substance users (especially injection drug users) are high and represent a public health problem that can be ameliorated with prevention and treatment. ${ }^{20}$ The high prevalence of substance use in Harlem suggests that access to social services in the community is particularly important to decrease rates of both drug use and its consequences. ${ }^{21}$

In this article, $\mathrm{CAB}$ members and CUES researchers present two studies carried out by the URC, one with service providers and the other with substance users, regarding barriers to access to social services for substance users in Harlem. We addressed two principal questions: (a) What were service providers' perceptions of access to services and information about services in their communities? and (b) What were substance users' perceptions of access to, and information about, the same services? We also addressed two secondary questions in these analyses: (a) Were service providers' perceptions of access to services different for providers who work in East versus Central Harlem? and (b) Did substance users who had experience with social services in the communities perceive different barriers to access than substance users who had less experience with social services?

\section{METHOD}

\section{Survey of Service Providers-Participants and Design}

The target population for the sample of service providers were those working in East and Central Harlem, New York City, in 2000, who provided services or referrals for substance users. East Harlem has historically been a predominantly Latino community, whereas Central Harlem has historically been a predominantly African American community. Although the two communities are administratively frequently regarded as one neighborhood, their residents consider the two communities to be distinct culturally and socially. Both East and Central Harlem are neighborhoods in the northern end of New York City's borough of Manhattan. For the purposes of this research, we used the following definition of East and Central Harlem: East Harlem was defined as the area beginning in the south at 96th Street, extending north to 119th Street, bordered on the west by 5th Avenue and on the east by the East River; Central Harlem was defined as the area spanning east-west from the Harlem River to Morningside Drive and north-south from 155th 
Street to 110th Street (excluding the area in East Harlem between 110th Street and 119th Street east of 5th Avenue). The boundaries were determined through discussion with community members involved with the URC.

The URC community liaison (EC, one of this article's authors), based in Harlem and with more than 10 years of social service experience in the community, in collaboration with the $\mathrm{CAB}$, compiled a database of social service agencies in Harlem that provided services or referrals for substance users. CUES investigators and CAB members, through an iterative process, developed a survey instrument. We mailed the survey instrument to 351 agencies in August 2000. In September 2000, we followed up with phone calls to the agencies that had not returned the completed survey. A community symposium organized by the CAB was held at the New York Academy of Medicine (NYAM) on October 26-27, 2000. We attended the symposium and encouraged service providers who had not yet completed the survey to do so. CUES researchers analyzed the data, and CUES researchers and $\mathrm{CAB}$ members interpreted the data. The study was reviewed and approved by the Institutional Review Board of NYAM.

\section{Instrument and Measures}

A 15-minute standardized, self-reported survey instrument was used. Development of the survey instrument was guided by $\mathrm{CAB}$ member experience of the salient issues and by the conceptual model articulated as a framework for URC research. CAB members who had firsthand experience with substance use issues (either as clients or as service providers) were particularly active in designing the survey instrument. The survey included questions about each respondent's age, race, what type of program they worked in, how long they had worked with this client population, how long they had worked in Harlem, and whether they had been to college. Service providers identified how easy it was to refer clients to appropriate service in the community, which groups of clients were most difficult to refer, and what problems they faced in referring clients.

To identify information about available services, we asked respondents to answer yes or no to the following question: "People who use drugs know enough about [service]." We asked this question for services that corresponded to the five principal social service areas applicable to drug users in the community: housing, job services, education, medical services, and drug-related services. These five social service areas summarize the work done by the social service agencies contacted. Job services included job opportunities and job training. Housing services included permanent housing, emergency shelters, how to avoid eviction, and temporary places to stay. Education services included literacy, general equivalency diploma (GED), and college programs. Medical services included mental health clinics, HIV services, Medicaid, and health clinics. Drug-related services included needle exchange, rehabilitation programs, drug detoxification programs, and methadone programs. This list of social services was developed by members of the $C A B$ and through three focus groups with substance users held at the CUES research storefront and guided by the researchers. Respondents were asked where they thought drug users got most of their information about each of the services listed. The choice of responses, also guided by the focus groups, included "word of mouth," "pamphlets and information booklets," "hear about them from outreach workers," "posters," and "other, please specify."

To assess providers' perceptions about users' difficulty accessing services, respondents were asked to answer yes or no to the following question: "Is it difficult for users to get into [service]?" Respondents were asked about the same services listed above. Respondents then identified the "main reason why it is difficult for drug users to access 
[each of the listed services]." Possible choices (determined through the focus groups with substance users) were the following: "They need a permanent address"; "they need too much paperwork or need ID"; "hard for users to follow all the rules"; "there aren't enough programs available, programs are overcrowded"; "programs keep changing, rules keep changing"; "they need Medicaid"; "the waiting list is too long"; "Users need to pay for program"; "programs don't accept clients with a jail record"; and "other, please specify."

\section{Survey of Substance Users-Participants and Design}

Persons older than age 18 who had used cocaine, crack, or heroin during the past 6 months were eligible for the study. For this study, we enrolled drug users in Harlem through street outreach during the period August 2000-January 2001. Project outreach workers approached drug users on the street, placed advertisements in service agencies, and handed out pamphlets to interested persons. New participants were also recruited by word of mouth from enrolled participants. Persons who agreed to participate in the study were interviewed by trained interviewers at a storefront research center in Central Harlem. The storefront in Central Harlem is a freestanding clinic where CUES staff workers interview participants enrolled in the research study and implement other public health interventions aimed at reducing risk behavior among substance users.

Questions for this study were administered as structured confidential interviews in the Central Harlem storefront. Participants first underwent a face-to-face screening interview. Once participants were found eligible for the study, trained interviewers explained the research protocol and obtained informed consent. A 45-minute survey instrument was administered by the interviewer, including questions pertaining to this study and to other research. After the interview, all participants were offered counseling and appropriate service referral. Participants received $\$ 15$ compensation at the end of each visit. CUES researchers analyzed the data, and CUES researchers and CAB members interpreted the data. The Institutional Review Board of NYAM approved the study.

\section{Instrument and Measures}

The survey instrument used in this research was developed in collaboration with the $\mathrm{CAB}$ and built on questions the researchers had used in previous studies. ${ }^{22}$ As in the first survey discussed here, development of the survey instrument was guided particularly by $\mathrm{CAB}$ members who had firsthand experience with substance use issues either as clients or as service providers. Participants were asked demographic characteristics such as age, sex, race, educational level, history of homelessness, and levels of income. Participants' drug-using practices were classified by method of ingestion and by type of drugs used in the last 2 months. Participants identified which services they had used throughout their life to obtain a measure of their familiarity with social services in their community.

To identify information about available services, we asked respondents to answer yes or no to the following question: "Do you know enough about [service] in your community?" We repeated the question for each of the same services described above. We then asked users to answer yes or no to the following question: "Do you think it is difficult for you to get into [service] if you need [it]?" The question was repeated again for the list of services above. We asked respondents to tell us the main reason they found it difficult to get into these services. Respondents were asked to choose an answer from the following: "need a permanent address"; "too much paperwork"; "hard to follow all the rules"; "not 
enough programs"; "programs keep changing"; "need Medicaid"; "waiting list too long"; "need to pay"; "jail record"; "not enough information"; "other, please specify."

\section{Statistical Analyses}

We compiled summary descriptive statistics of the service provider sample. CAB members suggested that stratifying service providers' responses by work in East/Central Harlem would be appropriate to improve our understanding of differences in provider perceptions in the two neighborhoods. We carried out two-tailed chi-square tests to examine differences between providers in East and Central Harlem for each of the demographic variables and for perceptions providers had about access to services. We compiled summary descriptive statistics of the drug user sample. We dichotomized the group by using the median number of services respondents had used. We carried out two-tailed chi-square tests to examine differences between users in each group for each of the demographic variables and for perceptions of users about access to services. We compared frequencies of yes responses to questions about social services between service providers and substance users.

\section{RESULTS}

\section{Service Provider Survey—Sample Characteristics}

We obtained completed surveys from 91 service providers in East and Central Harlem, a response rate of $25 \%$. The service providers responding were representative of the organizations in the sampling frame in terms of types of services provided and scope of service delivery. Most service provider respondents $(60 \%)$ worked in East Harlem (Table 1). Overall, the respondents were predominantly female (60\%), African American (37\%), and Latino (32\%). The mean age of the respondents was 44 years. Respondents had worked with their client population for a median of 10 years (range 0-35) and with their current agency for a median of 3 years (range 0-30). Significantly more providers in Central Harlem were African American (47\% vs. $30 \%$ in East Harlem), and more providers in East Harlem were Latino ( $42 \%$ vs. $17 \%$ in Central Harlem).

\section{Service Provider Perspectives on Access to Services}

More than one-third (37\%) of all service providers surveyed said that they had a somewhat or very difficult time finding the appropriate services to refer clients in East and Central Harlem. When asked about specific types of services that users have difficulty accessing, job and housing services were identified most frequently. Specifically, 74\% of providers said that users had a difficult time accessing job services; $62 \%$ said users had a difficult time accessing housing services (Table 2). Fewer providers identified barriers in access to drug-related services (56\%), education (56\%), and medical services (49\%). Service providers also said that users did not know enough about job (76\%) and housing $(61 \%)$ services.

Service providers gave three principal reasons for the difficulty substance users had in accessing services. First, lack of information was identified as an important barrier to accessing job-related and education services. Second, providers said that housing-related 
Table 1. Sample Characteristics of Social Service Provider Respondents, Harlem, New York City, 2000

\begin{tabular}{|c|c|c|c|c|}
\hline Variable & $\begin{array}{c}\text { Overall } \\
\text { Sample }(\%) \\
(N=91)\end{array}$ & $\begin{array}{c}\text { East } \\
\text { Harlem }(\%) \\
(n=55)\end{array}$ & $\begin{array}{c}\text { Central } \\
\text { Harlem }(\%) \\
(n=36)\end{array}$ & $\chi^{2} p$ Value* \\
\hline \multicolumn{5}{|l|}{ Sex } \\
\hline Female & 60.0 & 61.1 & 58.3 & 0.69 \\
\hline \multicolumn{5}{|l|}{ Age } \\
\hline$>40$ & 62.6 & 59.2 & 63.6 & 0.69 \\
\hline \multicolumn{5}{|l|}{ Race } \\
\hline African American & \multirow{2}{*}{$\begin{array}{l}37.1 \\
31.5\end{array}$} & 30.2 & 47.2 & \multirow[t]{2}{*}{0.04} \\
\hline Latino/Latina $^{\mathrm{a}}$ & & 41.5 & 16.7 & \\
\hline \multicolumn{5}{|l|}{ Education } \\
\hline \multirow[t]{2}{*}{ Some college } & 86.8 & 87.3 & 86.1 & 0.87 \\
\hline & $M \quad S D$ & $M \quad S D$ & $S D$ & $\begin{array}{c}t \text {-Test } \\
p \text { Value } * *\end{array}$ \\
\hline $\begin{array}{l}\text { Length of time working } \\
\text { with client population }\end{array}$ & $10.4(7.9)$ & $10.6(8.7)$ & $10.0 \quad(6.6)$ & 0.73 \\
\hline $\begin{array}{l}\text { Length of time working } \\
\text { in Harlem }\end{array}$ & $7.9(8.0)$ & $8.2(7.6)$ & $7.3 \quad(8.7)$ & 0.60 \\
\hline $\begin{array}{l}\text { Length of time working } \\
\text { at their agency }\end{array}$ & $5.5(6.3)$ & $6.2(6.6)$ & $4.5 \quad(5.8)$ & 0.21 \\
\hline
\end{tabular}

a. Other races in the study included White, Native American, and Native Hawaiian.

b. Length of time in years.

* Two-tailed chi-square $p$ value; test of no association between subgroups in East and Central Harlem. $* * t$ test for equal variances.

programs were insufficient. Third, drug users needing Medicaid were identified as a problem in accessing medical services and services directly related to drug abuse treatment. Too much paperwork was identified as the principal reasons for difficulty in accessing Medicaid.

A comparison of responses about information and access failed to reveal any significant differences between respondents in East and Central Harlem (results not shown).

\section{Substance User Survey-Sample Characteristics}

Among 353 drug users who were eligible for this study, $31 \%$ were female, $47 \%$ had less than high school education, $67 \%$ had used injection drugs at some point in their lives, and $39 \%$ had used injection drugs in the past 2 months (Table 3). Our sample was primarily African American (60\%) and Latino (29\%). Approximately three-quarters of the respondents $(76 \%)$ had an income of $\$ 5,000$ or less each year, $87 \%$ had been homeless at some point in their lives, and $52 \%$ had been homeless in the past 6 months.

Respondents had accessed a median of nine services in the past. Respondents who had been homeless at some point in their lives, respondents who had ever used injection drugs, and respondents who were HIV positive were likelier to have accessed more than nine services. 
Table 2. Service Providers' Perceptions About Access to Social Services in the Community, Harlem, New York City, $2000(N=91)$

\begin{tabular}{lcl}
\hline Service & $\begin{array}{c}\text { Providers Who Say Users Have a } \\
\text { Difficult Time Accessing Service (\%) }\end{array}$ & \multicolumn{1}{c}{$\begin{array}{c}\text { Principal Reason Why Service } \\
\text { Is Difficult to Access }\end{array}$} \\
\hline Job $^{\mathrm{a}}$ & 74.1 & $\begin{array}{l}\text { Not enough information available } \\
\text { Housing }^{\mathrm{b}}\end{array}$ \\
Drug related $^{\mathrm{c}}$ & 62.1 & $\begin{array}{l}\text { Not enough programs available } \\
\text { Education }^{\mathrm{d}}\end{array}$ \\
Medical $^{\mathrm{e}}$ & 56.5 & $\begin{array}{l}\text { Need Medicaid } \\
\end{array}$ \\
& 55.7 & Not enough information available \\
& 48.5 & \\
& & \\
& Providers Who Say Users & \\
Job $^{\mathrm{a}}$ & Do Not Know Enough & - \\
Housing $^{\mathrm{b}}$ & About a Particular Service (\%) & - \\
Drug related $^{\mathrm{c}}$ & 76.0 & - \\
Education $^{\mathrm{d}}$ & 60.9 & - \\
Medical $^{\mathrm{e}}$ & 35.9 & - \\
\hline
\end{tabular}

a. Job services included job opportunities and job training.

b. Housing services included permanent housing, emergency shelters, and temporary places to stay. c. Drug-related services included needle exchange, rehabilitation programs, and detox and methadone programs.

d. Education services included literacy, general equivalency diploma (GED), and college programs. e. Medical services included Medicaid, mental health clinics, HIV services, and health clinics.

\section{Substance User Perspectives on Access to Services}

Forty-five percent of all drug users said that they had a difficult time accessing job services, and 35\% said they had a difficult time accessing housing services. Fewer users identified barriers in access to medical services (17\%), education (10\%), and drug-related services (8\%) (Table 4). Drug users also said that they did not know enough about job $(57 \%)$ and housing $(51 \%)$ services. There were no significant differences between barriers identified by drug users who had accessed fewer or more than nine services (data not shown).

Substance users mentioned three main reasons for difficulty in accessing services: not enough information available about job and education programs, needing Medicaid to access medical and drug-related services, and not enough housing programs available. Too much paperwork was identified as the principal reason for their difficulty in accessing Medicaid (data not shown).

\section{DISCUSSION}

There were three principal observations from our study of service providers and substance users. First, service providers and substance users consistently reported difficulties accessing job services (including job opportunities and job training) and housing services (including permanent housing, emergency shelters, and temporary places to stay). 
Table 3. Selected Demographic Characteristics of Drug User Sample, Harlem, New York City, 2000 (in percentages)

\begin{tabular}{|c|c|c|c|c|}
\hline Variable & $\begin{array}{c}\text { Overall } \\
\text { Sample } \\
(N=353)\end{array}$ & $\begin{array}{c}\text { Drug Users } \\
\text { Who Have } \\
\text { Accessed Fewer } \\
\text { Than } 10 \text { Services }{ }^{\mathrm{a}} \\
(n=189)\end{array}$ & $\begin{array}{l}\text { Drug Users } \\
\text { Who Have } \\
\text { Accessed } 10 \text { or } \\
\text { More Services } \\
\quad(n=164)\end{array}$ & $\chi^{2} p$ Value* \\
\hline \multicolumn{5}{|l|}{ Sex } \\
\hline Female & 30.9 & 30.6 & 31.3 & 0.89 \\
\hline \multicolumn{5}{|l|}{ Age } \\
\hline $18-34$ & 21.8 & 24.3 & 18.9 & 0.14 \\
\hline $34-45$ & 53.0 & 54.5 & 51.2 & \\
\hline$\geq 45$ & 25.2 & 21.2 & 29.9 & \\
\hline \multicolumn{5}{|l|}{ Race } \\
\hline African American & 59.5 & 63.5 & 54.9 & 0.05 \\
\hline Latino $^{\mathrm{b}}$ & 29.2 & 28.6 & 29.9 & \\
\hline \multicolumn{5}{|l|}{ Education } \\
\hline$<$ High school & 47.3 & 50.3 & 43.9 & 0.23 \\
\hline \multicolumn{5}{|l|}{ Income } \\
\hline$\leq \$ 5,000 /$ year & 76.0 & 78.7 & 73.0 & 0.15 \\
\hline \multicolumn{5}{|l|}{ Homelessness } \\
\hline Ever & 86.7 & 82.5 & 91.5 & 0.01 \\
\hline \multicolumn{5}{|l|}{ IV drug use } \\
\hline Ever & 66.5 & 56.9 & 77.9 & 0.01 \\
\hline \multicolumn{5}{|l|}{$\mathrm{HIV}^{\mathrm{c}}$} \\
\hline Positive & 24.5 & 19.7 & 29.9 & 0.02 \\
\hline
\end{tabular}

a. Categorized by median number of services accessed.

b. Other subgroup including White, Native American, and Native Hawaiian.

c. Among individuals who have been tested for HIV $(n=316)$.

* Two-tailed chi-square $p$ value; test of no association between subgroups of users who have accessed fewer, or more, services.

Second, service providers and substance users identified lack of information as the principal barrier to accessing job and education services and not enough programs as the principal barrier to accessing housing services. Both groups identified needing Medicaid as the principal barrier to accessing health- and drug-related services and identified too much paperwork as a barrier to accessing Medicaid. Third, although the users we sampled were more likely to be familiar with social services if they were HIV positive, had used injection drugs, or had ever been homeless, users who were more familiar and those who were less familiar with social services identified similar barriers to accessing health- and drugrelated services.

The observations in our study build on existing research regarding drug use and access to care. Among vulnerable populations, the link between difficulty in accessing services and adverse health is well established. ${ }^{23}$ Race and socioeconomic class influence access to medical care. ${ }^{23,24}$ Traditionally underserved populations, such as substance users, pose particular challenges for service provision. ${ }^{25}$ Access to services for these groups is likely related to factors other than service availability alone. Although lack of funding has been documented as a major barrier to expanding services, ${ }^{26}$ other research has documented that increasing disbursement of funding for health-related services failed to increase use 
Table 4. Perceptions of Drug Users About Access to Social Services in the Community, Harlem, New York City, $2000(N=353)$

\begin{tabular}{lcl}
\hline Service & $\begin{array}{c}\text { Users Who Have a } \\
\text { Difficult Time } \\
\text { Accessing Service (\%) }\end{array}$ & \multicolumn{1}{c}{$\begin{array}{c}\text { Principal Reason } \\
\text { Why Service Is } \\
\text { Difficult to Access }\end{array}$} \\
\hline Job $^{\mathrm{a}}$ & 45.2 & $\begin{array}{l}\text { Not enough information available } \\
\text { Housing }^{\mathrm{b}}\end{array}$ \\
Medical $^{\mathrm{e}}$ & 34.9 & $\begin{array}{l}\text { Not enough programs available } \\
\text { Education }^{\mathrm{d}}\end{array}$ \\
Drug related $^{\mathrm{c}}$ & 17.3 & Need Medicaid \\
& 10.4 & Not enough information available \\
& 8.1 & \\
\hline Job $^{\mathrm{a}}$ & Users Do Not Know & \\
Housing $^{\mathrm{b}}$ & Enough About a & - \\
Medical $^{\mathrm{e}}$ & Particular Service (\%) & - \\
Education $^{\mathrm{d}}$ & 56.7 & - \\
Drug related $^{\mathrm{c}}$ & 50.7 & - \\
\hline
\end{tabular}

a. Job services included job opportunities and job training.

b. Housing services included permanent housing, emergency shelters, and temporary places to stay. c. Drug-related services included needle exchange, rehabilitation programs, and detox and methadone programs.

d. Education services included literacy, general equivalency diploma (GED), and college programs. e. Medical services included Medicaid, mental health clinics, HIV services, and health clinics.

of services significantly. ${ }^{27}$ This indicates that other barriers to access must be addressed to improve service accessibility. A limited body of work has identified cost of services, ${ }^{28}$ language and culture ${ }^{29}$ and income ${ }^{30}$ as important barriers to care among drug users. Our research documents that a lack of information, not enough programs available, and difficulties accessing Medicaid (too much paperwork) are the principal reasons why drug users in Harlem experience difficulty accessing services.

Several study limitations should be noted. Without a definitive formal list of service providers working in Harlem, our community liaison and $\mathrm{CAB}$ members generated an original list from which to sample providers. The completeness of this list cannot be precisely determined. Although the response rate for our mailed survey was low, it was within the range described in the broader literature of response rates for mailed surveys. ${ }^{31,32}$ Although the respondents who did complete the survey worked for service agencies that were representative of the sampling frame, the degree to which our survey response introduces a potential selection bias is difficult to determine.

Our sample of substance users consisted of users who volunteered to participate in our research when approached by street outreach workers. In the absence of a denominator estimate of substance users in Harlem, we cannot estimate a response rate among users. Although the possibility exists that these users may be systematically different from other substance users, this strategy has been used successfully in several other studies of drug users. ${ }^{22,33}$ We attempted to minimize potential bias in this regard by mapping the community and recruiting from many sites within the neighborhoods. In addition, although we asked substance users recruited in Harlem about services in their community, it is possi- 
ble that some users were referring to their knowledge of services in communities other than Harlem.

We are hesitant to draw conclusions about the generalizability of our results to providers, or substance users, in other communities. Although we attempted to construct comparable survey questions for the service providers and substance users, comparison of results from different surveys conducted with different sampling frames must be done cautiously. We intended our results to guide New York City URC activities. We asked service providers about their perceptions of users' barriers to services and compared these answers with drug users' responses to analogous questions. Our analysis indicates that service providers accurately describe the services to which substance users have most limited access. A consistently greater proportion of service providers in our study identified the presence of barriers to access than did substance users themselves. The implications of this finding are unclear in light of our small sample of service providers but do suggest directions for future research.

\section{Implications for Service Provision in Harlem}

The principal aim of this study was to identify barriers to access to social services for substance users in Harlem, New York City. The study was guided by a conceptual model of social determinants of health. This model, developed through a collaborative process with community members, identified access to services as a key social determinant and one of the early priorities for URC research and intervention. Development of our conceptual model of social determinants was itself guided by existing needs assessments that had been carried out in Harlem. The studies described in this article then arise from a participatory process that considered existing information, integrated it into a cogent theoretical framework, and developed focused research that can guide specific interventions.

Published reports suggest that needle exchange programs, HIV-related services, and pharmacies might have a role in improving injection drug users' access to services. ${ }^{34-39} \mathrm{In}$ addition, the combination of active street outreach, ${ }^{40}$ advocacy, ${ }^{41}$ use of peer counselors, ${ }^{42}$ and empowering of substance users ${ }^{43}$ can improve substance users' access to services in communities. We designed our research to identify barriers to access in Harlem that could benefit from interventions. Results of this research are consistent with a model of social determinants whereby institutional and organizational issues (e.g., availability of services) beyond individual-level factors contribute to health and well-being. Interventions designed by URC members will build both on previous work and on this research.

Our research provides three avenues for intervention in Harlem and identifies an issue that will pose a particular challenge for the New York City URC. First, information about particular services is insufficient (particularly services related to fundamental living conditions such as housing and employment). An early intervention in this regard is a user "Survival Guide" (described in a complementary article from our URC, also appearing in this journal). ${ }^{44}$ Second, programs are needed that offer a range of comprehensive services to assist substance users' access to services that help with finding jobs and housing. The $\mathrm{CAB}$ is currently considering different options that might best meet this need, including a multipurpose service center designed to meet the multiple needs of the most vulnerable users. Third, too much paperwork was identified as a barrier to accessing health insurance, and accessing health insurance was a barrier to other services. We are currently considering specific action in this regard, including longer term advocacy and further research that examines the implications of social service policy interventions in Harlem. 
Addressing the limited availability of housing services identified as a problem by both groups surveyed will be a challenge for our URC. Effecting improvement in housing services will require long-term commitment to improving macro-level features of the Harlem social environment. The $\mathrm{CAB}$ has chosen to work first on small-scale interventions that address some of the more easily modifiable barriers to access identified in our surveys (e.g., limited information). However, we have also identified social conditions that affect substance users that are shaped by broader social processes. This project provided our URC team of community members, consumers, service providers, and researchers with considerable experience in collaboration. We hope that as the URC partnership develops, it can tackle more ambitious initiatives that address macro-level factors such as limited housing services. A final point in this regard is that some of the barriers identified in this research (e.g., availability of services) had not been explicitly described as important factors in our guiding conceptual model. This identification of new domains that were not previously in our model of social determinants will guide the $\mathrm{CAB}$ in further developing the conceptual framework.

\section{Conclusion}

Through a community-based participatory research framework, we identified substance use as a priority for research and intervention in Harlem, formulated a conceptual model that posits access to services as an important determinant of substance users' health, and carried out a study that aimed to improve our understanding of barriers to access in the community. Our surveys of substance users and of service providers identified key services about which there is a lack of information (particularly information related to employment and housing) and the particular barriers to access that require systematic intervention (not enough programs, lack of information, and too much paperwork). Our URC is currently using this knowledge to formulate interventions and to refine our model of social determinants of health.

\section{References}

1. Community Health Atlas. New York, United Hospital Fund, 1999.

2. Centers for Disease Control and Prevention: Division of HIV/AIDS Prevention: Basis Statistics. Retrieved on November 28, 2000, from http://www.cdc.gov/hiv/stats.htm

3. U.S. Department of Commerce, Bureau of the Census [1995]: Topologically Integrated Geographic Encoding and Referencing System [Data file]. Retrieved on October 30, 2000, from http://www.census. gov/geo/www/tiger

4. Freudenberg N: Cross-site evaluation of the U.S. Centers for Disease Control and Prevention Urban Research Centers Program. J Urban Health, in press.

5. Cohen S, Kessler RC, Gordon LU: Strategies for measuring stress in studies of psychiatric and physical disorders, in Cohen S, Kessler RC, Gordon LU (eds.): Measuring Stress: A Guide for Health and Social Scientists. New York, Oxford University Press, 1995, pp. 3-26.

6. McEwen BS, Stellar E: Stress and the individual: Mechanisms leading to disease. Arch Intern Med 153:2093-2101, 1993.

7. Steptoe A: The links between stress and illness. J Psychosom Res 35:633-644, 1991.

8. Kessler RC, Price R, Wortman C: Social factors in psychopathology: Stress, social support, and coping processes. Ann Rev Psych 36:531-572, 1985.

9. Link B, Phelan JC: Editorial: Understanding sociodemographic differences in health-The role of fundamental social causes. Am J Public Health 86(4):471-472, 1996. 
10. Sutton L: Report on Needs Assessments Conducted on East Harlem: 1989-1999. New York, Center for Urban Epidemiologic Studies, 1999.

11. Marmor TR, Barer ML, Evans RG: The determinants of a population's health: What can be done to improve a democratic nation's health status, in Evans RG, Barer ML, Marmor TR (eds.): Why Are Some People Healthy and Others Not? New York, Aldine, 1994.

12. McKeown TJ: The Origins of Human Disease. London, Blackwell, 1988.

13. Blendon R, Aiken L, Freeman H, Corey C: Access to medical care for Black and White Americans. JAMA 261:278-281, 1989.

14. Williams DR: Socioeconomic differentials in health: A review and redirection. Soc Psych Quarterly 53(2):81-99, 1990.

15. Trevino FM, Moyer ME, Valdez RB, Stroup-Benham CA: Health insurance coverage and utilization of health services by Mexican Americans, mainland Puerto Ricans, and Cuban Americans. JAMA 265:2233-2237, 1991.

16. Schulman KA, Berlin JA, Harless W, et al: The effect of race and sex on physicians' recommendations for cardiac catheterization. New Engl J Med 340:618-626, 1989.

17. Epstein AE, Ayanian JZ, Keogh JH: Racial disparities in access to renal transplantation. New Engl J Med 343(21):1537-1544, 2000.

18. Kotchen JM, Shakoor-Abdullah B, Walker WE, et al: Hypertension control and access to medical care in the inner city. Am J Pub Health 88(11):1696-1699, 1998.

19. Schulman KA, Rathore SS, Lenert LA, et al: The effects of patient sex and race on medical students' ratings of quality of life. Am J Med 108(7):561-566, 2000.

20. Rose D: The epidemiology of HIV infection and AIDS in East and Central Harlem, NY. Mt Sinai J Med 59:493-497, 1992.

21. Fullilove RE, Fullilove MT, Northridge ME, et al: Risk factors for excess mortality in Harlem findings from the Harlem Household Survey. Am J Prev Med 16(suppl. 3):22-28, 1999.

22. Vlahov D, Munoz A, Anthony JC, et al: Association of drug injection patterns with antibody to human immunodeficiency virus Type I among intravenous drug users in Baltimore, Maryland. Am J Epidemiol 132:847-856, 1990.

23. Mandelblatt JS, Yabroff KR, Kerner JF: Equitable access to cancer services: A review of barriers to quality care. Cancer 86:2378-2390, 1999.

24. Weissman G, Melchior L, Huba G, et al: Women living with drug abuse and HIV disease: Drug abuse treatment access and secondary prevention issues. J Psychoactive Drugs 279(4):401411, 1995.

25. Booth RE, Kwiatkowski CF, Weissman G: Health-related service utilization and HIV risk behaviors among HIV infected injection drug users and crack smokers. Drug Alcohol Depend 55(1-2):69-78, 1999.

26. Andrulis DP: Access to care is the centerpiece in the elimination of socioeconomic disparities in health. Ann Intern Med 129:412-416, 1998.

27. Helms CM, Damiano PC: Health care system reform and public health: Promoting the safety net. Arch Fam Med 44(1):12-13, 1995.

28. Krniawan RK, Astrawinata DA, Kumalawati J, et al: Free-of-charge HIV/AIDS testing and counselling. Int Conf AIDS [Abstract no. TuPeD3659], July 9-14, 2000.

29. Grigaitis A: Language and culture as a barrier to services for HIV+ IDUs. Int Conf AIDS [Abstract no. TuPeD3710], July 9-14, 2000.

30. Soletti J, De Montaigne A-B, Chauvin P: Social inequalities in access to treatment in France, as observed among people living with HIV/AIDS attending Aides services: A multicentric crosssectional study. Int Conf AIDS [Abstract no. TuPpB1163], July 12-14, 2000.

31. Gibson PJ, Koepsell TD, Diehr P, Hale C: Increasing response rates for mailed surveys of Medicaid clients and other low-income populations. Am J Epidemiol 149(11):1057-1062, 1999.

32. Donaldson GW, Moinpour CM, Bush NE, et al: Physician participation in research surveys: A randomized study of inducements to return mailed research questionnaires. Eval Health Prof 22(4):427-441, 1999. 
33. Diaz T, Des Jarlais DC, Vlahov D, et al: Factors associated with prevalent Hepatitis C: Differences among young adult injection drug users in Lower and Upper Manhattan, New York City. Am J Public Health 91:23-30, 2001.

34. Heimer R: Can syringe exchange serve as a conduit to substance use treatment? J Subst Abuse Treat 15:183-191, 1998.

35. Brooner R, Kidorf M, King V, et al: Drug abuse treatment success among needle exchange participants. Public Health Rep 113 (suppl. 1):129-139, 1998.

36. Strathdee S, Celentano D, Shah N, et al: Needle-exchange attendance and health care utilization promote entry into detoxification. J Urban Health 76(4):448-460, 1999.

37. Cymerman P, Sanchez A, Touze G, et al: Improving injecting drug users' access to prevention through pharmacies. Int Conf AIDS [Abstract no. WePeD4825], July 9-14, 2000.

38. McCoy HV, Aversa IS, Chitwood DD, et al: Access to health services for HIV positive chronic drug users. Int Conf AIDS [Abstract no. 14141], June 28-July 3, 1998.

39. Lawlor BD, Newmeyer JA, Fergusson BC, et al: Improving access to care: An innovative model. Int Conf AIDS [Abstract no. M.D. 4131], June 16-21, 1991.

40. Agnoletto V, Tradati C, Ceserani N, et al: Street work and needle exchange machines as complementary strategies of HIV harm reduction among active drug users: An Italian model. Int Conf AIDS [Abstract no. WS-D09-4], June 6-11, 1998.

41. Serrano Y, Goldsmith D: Street outreach strategies for intravenous drug and crack users, their sexual partners, and addicted prostitutes at risk for HIV. Int Conf AIDS [Abstract no. Th.D.P.65], June 4-9, 1989.

42. Vaughn B: A street outreach program for hard to reach individuals. Int Conf AIDS [Abstract no. pub. C. 1255], July 7-12, 1996.

43. Forbes A: Each one teach one: The individual and community-wide impact of empowering women with HIV. Int Conf AIDS [Abstract no. 33556], June 28-July 3, 1998.

44. Factor SH, Galea S, Garcia de Duenas Geli L, et al: Development of a "survival" guide for substance users in Harlem, New York City. Health Educ Behav 29(3):312-325 